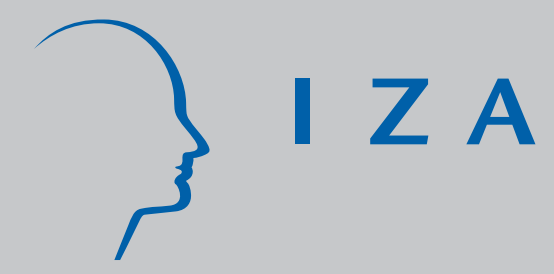

IZADP No. 2739

High Relocation Costs in Search-Matching Models: Theory and Application to Spatial Mismatch

Yves Zenou

April 2007 


\title{
High Relocation Costs in Search-Matching Models: Theory and Application to Spatial Mismatch
}

\author{
Yves Zenou \\ Research Institute of Industrial Economics, \\ GAINS, CEPR and IZA
}

Discussion Paper No. 2739

April 2007

IZA

P.O. Box 7240

53072 Bonn

Germany

Phone: $+49-228-3894-0$

Fax: +49-228-3894-180

E-mail: iza@iza.org

\begin{abstract}
Any opinions expressed here are those of the author(s) and not those of the institute. Research disseminated by IZA may include views on policy, but the institute itself takes no institutional policy positions.

The Institute for the Study of Labor (IZA) in Bonn is a local and virtual international research center and a place of communication between science, politics and business. IZA is an independent nonprofit company supported by Deutsche Post World Net. The center is associated with the University of Bonn and offers a stimulating research environment through its research networks, research support, and visitors and doctoral programs. IZA engages in (i) original and internationally competitive research in all fields of labor economics, (ii) development of policy concepts, and (iii) dissemination of research results and concepts to the interested public.
\end{abstract}

IZA Discussion Papers often represent preliminary work and are circulated to encourage discussion. Citation of such a paper should account for its provisional character. A revised version may be available directly from the author. 


\title{
ABSTRACT
}

\section{High Relocation Costs in Search-Matching Models: Theory and Application to Spatial Mismatch*}

\begin{abstract}
We develop a standard search-matching model in which mobility costs are so high that it is too costly for workers to relocate when a change in their employment status occurs. We show that, in equilibrium, wages increase with distance to jobs and commuting costs because firms need to compensate the transportation cost difference between the employed and unemployed workers at each location in the city. We also show that the equilibrium land rent is negatively affected by the unemployment benefit because an increase in the latter induce firms to create less jobs, which, in turn, reduces the competition in the land market. We then use this model to provide a mechanism for the observed spatial mismatch between where black workers live and where jobs are. Because blacks and whites differ by their contact rate, we show that the former reside far away from jobs, have higher unemployment rates and lower wages. This is because the housing market amplifies the negative effects of the labor market by creating additional frictions.
\end{abstract}

JEL Classification: D83, J15, J64, R14

Keywords: $\quad$ search frictions, spatial frictions, efficiency, spatial mismatch hypothesis

Corresponding author:

Yves Zenou

Research Institute of Industrial Economics

Box 55665

10215 Stockholm

Sweden

E-mail: yves.zenou@ifn.se 


\section{Introduction}

It is commonly observed that residential mobility is limited because of different costs. In particular, transaction costs, which include transaction taxes such as capital gain taxes and ad valorem taxes that are proportional to the housing value (e.g. stamp duties and sale taxes), are substantial barriers to mobility (see e.g. van Ommeren and van Leuvensteijn, 2005). It has also been observed that homes tend to be less mobile than jobs. For example, Manning (2003) argues that approximately 20\% of workers have job tenure less than a year compared to $10 \%$ with residential tenure of less than a year. These features can explain, in particular, why workers do not always change location as soon as they change their employment status.

The aim of this paper is to develop a spatial search-matching model in which mobility costs are so high that it is too costly for workers to relocate when a change in their employment status occurs. In particular, we explicitly model the interaction between the labor and the land market so that wages, unemployment, job creation, housing prices and location are endogenous.

There is by now a small literature on urban search models (Zenou, 2007). Most of these models (Simpson, 1992; Wasmer and Zenou, 2002; Sato, 2001; 2004; Smith and Zenou, 2003) assume no mobility costs so that workers relocate as soon as their employment status changes. Very few authors have incorporated positive residential relocation costs in a spatial search model. Wasmer and Zenou (2006) consider both mobile and immobile workers. When hit by a job-destruction shock, the latter decide to stay at the same location whereas the former optimally relocate. They show that, compared to the model with no relocation costs, a middle area will emerge in the city where all workers are immobile. This model is however very cumbersome and the implications in the labor market are difficult to analyze. Selod and Zenou (2006) have a model with high relocation costs but again the labor-market outcomes are not fully determined (for example, the wage is exogenous). Coulson et al. (2001) develop a search model in a duocentric and assume no mobility costs within an area and positive costs between the two areas. Contrary to our approach, their focus is on the labor-market outcome differences between the areas so that, in particular, the intra analysis of the land market (i.e. where do workers locate in the city and what is the price of land at each location in the city) is not analyzed. Finally, Van Ommeren and Rietveld (2007) develop an interesting search-matching model with high residential relocation costs but assume that 
space is homogenous so that there is no difference in housing prices over space.

We believe that the present paper is the first attempt to introduce high relocation costs in an intra-city model where the analysis of the land market (Fujita, 1989) and the labor market with job-matching (Pissarides, 2000) is explicitly considered.

To be more precise, we develop a standard search-matching model in which workers have very high-relocation costs so that they stay at their location when they are hit by a shock and change their employment status. We assume perfect capital markets with a zero interest rate, so workers only care on the fraction of time they are employed and unemployed, and firms on the fraction of time they have a filled and a vacant job. We characterize the urbanland use equilibrium as well as the labor-market equilibrium. We show, in particular, that wages increase with distance to jobs and commuting costs because firms need to compensate the transportation cost difference between the employed and unemployed workers at each location in the city. We also show that the equilibrium land rent is positively affected by workers' productivity because an increase in the latter induces firms to create more jobs, which, in turn, increases the competition in the land market. An other interesting result is that higher unemployment benefits leads to lower land prices because of the induced effect on job creation. We also demonstrate that the equilibrium is not efficient and derive a spatial Pissarides-Hosios condition. We then extend this model so that search intensity becomes a function of distance to jobs because remote workers tend to have less information about jobs. All our previous results are robust to this extension.

The main advantage of our model is that it is very simple so that it can be used for further applications. This is what is done in the last section of the paper where we provide a model explaining the observed spatial mismatch between where black workers live and where jobs are. Indeed, first formulated by Kain (1968), the spatial mismatch hypothesis states that, residing in urban segregated areas distant from and poorly connected to major centres of employment growth, black workers face strong geographic barriers to finding and keeping well-paid jobs. In the US context, where jobs have been decentralized and blacks have stayed in the central parts of cities, the main conclusion of the spatial mismatch hypothesis is that distance to jobs is the main cause of high unemployment rates and low earnings among blacks. Since Kain's study, hundreds of others have been conducted trying to test the spatial mismatch hypothesis (see, in particular, the literature survey by Ihlanfeldt and Sjoquist, 1998). The usual approach is to relate a measure of labour-market outcomes, 
typically employment or earnings, to another measure of job access, typically some index that captures the distance between residences and centres of employment. The bulk of the evidence confirms that distance to jobs indeed leads to adverse labor-market outcomes for black workers in the US (Ihlanfeldt and Sjoquist, 1998). ${ }^{1}$

Despite this abundant empirical literature, theoretical models have emerged only recently, which probably explains why the mechanisms of spatial mismatch has long remained unclear and not properly tested (Gobillon et al., 2007). In the present paper, we propose the following explanation. Black and white workers only differ by their contact rate with firms, which implies that the returns to search are lower for black workers. As a result, they are more often unemployed and thus reside farther away from jobs. Since, for a given search effort, workers who live far away from jobs have few chances to find a job because they get little information on distant job opportunities, this location pattern implies that black workers search less intensively than whites, which increases even more their unemployment rate. Therefore, whites end up having higher wages and lower unemployment rates. So, in this model, because blacks and whites differ by their contact rate (because, for example, they have different social networks), they end up with very different adverse labor-market outcomes. What is interesting here is that the housing market amplifies the effects of the labor market by creating additional frictions.

The rest of the paper is organized as follows. In the next section, we present the basic model while the steady-state equilibrium is analyzed in section 3. In section 4, we extend the basic model to take into account the fact that distance to jobs negatively affects search intensity. In section 5, we apply the previous model to explain the segregation and adverse labor-market outcomes of black workers. Finally, section 6 concludes.

\section{The model}

Consider a continuum of equally productive workers whose mass is $N$ and who are uniformly distributed along a linear and closed city. All land is owned by absentee landlords and all firms are exogenously located in the Business District (BD hereafter). There is no vacant land. The $\mathrm{BD}$ is a unique employment center located at one end of the linear city. In a

\footnotetext{
${ }^{1}$ In Europe, there are also evidence of a spatial mismatch for ethnic minorities. See, in particular, Gobillon och Selod (2007) for France, and Patacchini and Zenou (2005) for the UK.
} 
centralized city, it corresponds to the Central Business District, whereas in a completely decentralized city, it represents suburban employment. Workers are risk neutral, optimally decide their place of residence between the BD and the other end of the city, and all consume the same amount of land (normalized to 1 for simplicity). Without loss of generality, the density of residential land parcels is taken to be unity, so that there are exactly $x$ units of housing within a distance $x$ from the BD. Relocation costs are assumed to be very high so that workers do not relocate after a change in their employment status.

Job matching There is a continuum of firms whose mass is $M$. A firm is a unit of production that can either be filled by a worker whose production is $y$ units of output or be unfilled and thus unproductive. In order to find a worker, a firm posts a vacancy. A vacancy can be filled according to a random Poisson process. Similarly, workers searching for a job will find one according to a random Poisson process. In aggregate, these processes imply that there is a number of contacts per unit of time between the two sides of the market that are determined by the following matching function: ${ }^{2}$

$$
M(\bar{s} u N, V)
$$

where $\bar{s}$ is the average search efficiency of the unemployed workers, $u N$ and $V$ the total number of unemployed ( $u$ is the unemployment rate) and vacancies, respectively. It is assumed here that $s=\bar{s}$, so each worker provides the same search effort $s$, which is exogenous. ${ }^{3}$ As in the standard search-matching model (see e.g. Mortensen and Pissarides, 1999, and Pissarides, 2000), we assume that $M($.$) is increasing both in its arguments, concave and$ homogeneous of degree 1 (or equivalently has constant return to scale). Thus, the rate at which vacancies are filled is $M(s u N, V) / V$. By constant return to scale, it can be rewritten as

$$
M(1 / \theta, 1) \equiv q(\theta)
$$

where

$$
\theta=\frac{V}{s u N}
$$

\footnotetext{
${ }^{2}$ This matching function is written under the assumption that the city is monocentric, i.e. all firms are located in one fixed location.

${ }^{3}$ This assumption is relaxed in section 4 .
} 
is a measure of labor market tightness in efficiency units and $q(\theta)$ is a Poisson intensity. By using the properties of $M($.$) , it is easily verified that q^{\prime}(\theta) \leq 0$ : the higher the labor market tightness, the lower the rate at which firm fill their vacancy. Similarly, the rate at which an unemployed worker with search intensity $s$ leaves unemployment is

$$
\frac{s}{\bar{s}} \frac{M(\bar{s} u N, V)}{u N} \equiv s \theta q(\theta)
$$

Again, by using the properties of $M($.$) , it is easily verified that [\theta q(\theta)]^{\prime} \geq 0$ : the higher the labor market tightness, the higher the rate at which workers leave unemployment since there are relatively more jobs than unemployed workers. So here the higher the search intensity $s$ (unemployed search more actively for jobs), the higher is this rate $s \theta q(\theta)$. Finally, the rate at which jobs are destroyed is exogenous and denoted by $\delta$.

If, in this model, there are no frictions, then unemployment and vacancies disappear, and jobs are found and filled instantaneously. Indeed,

$$
\lim _{\theta \rightarrow 0}[\theta q(\theta)]=\lim _{\theta \rightarrow+\infty} q(\theta)=0
$$

and

$$
\lim _{\theta \rightarrow+\infty}[\theta q(\theta)]=\lim _{\theta \rightarrow 0} q(\theta)=+\infty
$$

That is, if $\theta \rightarrow 0$, then the number of unemployed is infinite and thus firms filled their job instantaneously (no frictions on the firm's side), whereas if $\theta \rightarrow 0$, then the number of vacancies is infinite and thus workers find a job instantaneously (no frictions on the worker's side).

Workers' expected utility Each individual is identified with one unit of labor. Each employed worker goes to the BD to work and incurs a fixed monetary commuting cost $\tau$ per unit of distance. When living at a distance $x$ from the CBD, he/she also pays a land rent $R(x)$, consumes 1 unity of land, and earns a wage $w_{L}$ (that will be determined at the labor market equilibrium). ${ }^{4}$ The instantaneous (indirect) utility of an employed worker located at a distance $x$ from the BD is thus given by:

$$
W_{L}(x)=w_{L}(x)-\tau x-R(x)
$$

\footnotetext{
${ }^{4}$ The subscript $L$ refers to the employed whereas the subscript $U$ refers to the unemployed.
} 
We will show below that the wage is indeed a function of $x$, the distance to jobs. Concerning the unemployed workers, they commute less often to the CBD since they mainly go there to search for jobs. So, we assume that they incur a commuting cost $s \tau$ per unit of distance, where, as stated above, $0<s \leq 1$ is a measure of search intensity or search efficiency. For example $s=1$ would mean that the unemployed workers search very intensively so that they go to the CBD as often as the employed workers. ${ }^{5}$ The instantaneous (indirect) utility of an unemployed worker residing at a distance $x$ from the CBD is equal to:

$$
W_{U}(x)=w_{U}-s \tau x-R(x)
$$

As stated above, changes in the employment status of workers are governed by a Poisson process in which $s \theta q(\theta)$ is the job acquisition rate and $\delta$ is the exogenous job separation rate. At the steady state, flows into and out of unemployment must be equal, i.e.

$$
(1-u) N \delta=u N \theta q(\theta)
$$

Therefore, the steady-state unemployment rate is given by:

$$
u=\frac{\delta}{\delta+s \theta q(\theta)}
$$

As it is well-known in a Poisson process, the steady-state unemployment rate $u=U / N$ and employment rate $1-u$ correspond to the respective fractions of time a worker remains unemployed and employed over his/her infinite lifetime. We are thus able to calculate the expected utility of workers. To do that, we assume perfect capital markets with a zero interest rate, ${ }^{6}$ i.e. $r \rightarrow 0$. With perfect capital markets, workers are able to smooth their disposable income over time so that at any moment in time, the disposable income of a worker is equal to his/her average net income over the job cycle. Therefore, the expected utility of a worker residing in $x$ is given by:

$$
\begin{aligned}
E W(x) & =(1-u) W_{L}(x)+u W_{U}(x) \\
& =w_{L}(x)-\tau x-R(x)-\frac{\delta\left[w_{L}(x)-w_{U}-(1-s) \tau x\right]}{\delta+s \theta q(\theta)}
\end{aligned}
$$

\footnotetext{
${ }^{5}$ We could also introduce other search costs that are not-distance related. This would complicate the model without altering any of our results.

${ }^{6}$ When there is a zero interest rate, workers have no intrinsic preference for the present so that they only care about the fraction of time they spend employed and unemployed. Therefore, the expected utilities are not state dependent.
} 
Observe that in order to write this expected utility, we have assumed that, because workers are able to smooth their income over time, a worker's residential location remains fixed as he enters and leaves unemployment. In other words, after a change in his/her employment status, the worker does not relocate.

A steady-state equilibrium requires solving simultaneously an urban land use equilibrium and a labor market equilibrium. It is convenient to present first the latter and then the former.

\section{Steady-state equilibrium and welfare}

\subsection{Labor-market equilibrium}

Firms' expected utility Let us first determine the expected utility of firms when $r \rightarrow 0$. The instantaneous profit function for a firm hiring a worker is given by:

$$
\Pi_{F}(x)=y-w_{L}(x)
$$

whereas for a firm with a vacant job, it is equal to:

$$
\Pi_{V}=-c
$$

where $c$ is the cost of holding a vacancy. As stated above, there is a Poisson process on the firm's side in which $q(\theta)$ is the job-contact rate and $\delta$ is the exogenous job-separation rate. At the steady state, flows into and out of vacancies are equal, which is equivalent to:

$$
v M q(\theta)=\delta(1-v) M
$$

Observe that here the vacancy rate $v$ is the number of vacant jobs as a fraction of the total number of firms, i.e. $v=V / M$ and not as it is usually defined (Pissarides, 2000) as a fraction of the total labor force $N$. Observe also that $\delta(1-v) M=\delta(1-u) N$ and thus (8) can also be written as:

$$
v M q(\theta)=\delta(1-u) N
$$


Therefore, solving (8) gives the value of the vacancy rate $v$ as: ${ }^{7}$

$$
v=\frac{\delta}{\delta+q(\theta)}
$$

Note that the total number of jobs $M$ is defined as:

$$
M=\underbrace{(1-u) N}_{\text {Total filled jobs }}+\underbrace{v M}_{\text {Total vacant jobs }}
$$

which using (1) is equivalent to:

$$
\frac{M}{N}=\frac{1-u}{1-v}=\frac{1-u}{1-\theta s u}
$$

The unemployment rate $u$ is given by (6) and $\theta$ will be determined by a free-entry condition. When $u$ and $\theta$ are determined, then $M / N$ will adjust in order for (11) to be true.

With zero interest rate, the expected profit of a firm $E \Pi$ is therefore equal to:

$$
\begin{aligned}
E \Pi(x) & =(1-v) \Pi_{F}(x)+v \Pi_{V} \\
& =y-w_{L}(x)-\frac{\delta\left[y-w_{L}(x)+c\right]}{\delta+q(\theta)}
\end{aligned}
$$

Wage determination The usual assumption about wage determination (Pissarides, 2000) is that, at each period, the total surplus is shared through a generalized Nashbargaining process between the firm and the worker. Let us determine the surplus of workers and firms. When a worker located at $x$ accepts a job offer, he/she will get an expected utility of $E W(x)$ defined by (7). His/her threat point, i.e. the utility obtained if he/she does not accept the job offer (the negotiation fails), is given by:

$$
W_{U}(x)=w_{U}-s \tau x-R(x)
$$

Indeed, since all firms are identical, all job offers will be the same, and thus, if a worker refuses a job offer today, he/she now that he/she will refuse all job offers in the future. As

${ }^{7}$ Solving (9) would lead to

$$
v=\frac{\delta}{q(\theta)} \frac{N}{M}(1-u)
$$

which using (6) gives:

$$
\theta=\frac{v M}{s u N}
$$

which is equation (1). 
a result, the worker will get all his/her life the same utility of being unemployed, which is equal to $W_{U}(x)$ since $r \rightarrow 0$. Thus the surplus for workers located at $x$ of accepting a job offer is equal to:

$$
\begin{aligned}
S_{W} & =E W(x)-W_{U}(x)=\left[\frac{s \theta q(\theta)}{\delta+s \theta q(\theta)}\right]\left[w_{L}-w_{U}-(1-s) \tau x\right] \\
& =(1-u)\left[W_{L}(x)-W_{U}(x)\right]
\end{aligned}
$$

The value of the surplus is easy to understand since it means that, by accepting a job offer, the gain is the instantaneous surplus of being employed, i.e. $W_{L}(x)-W_{U}(x)$, during the fraction of time the worker is employed, i.e. $1-u$. Similarly, for firms, if the negotiation fails, the firm will obtain for ever $\Pi_{V}$ and thus the surplus is equal to:

$$
\begin{aligned}
S_{F} & =E \Pi-\Pi_{V}=\left[\frac{q(\theta)}{\delta+q(\theta)}\right]\left(y-w_{L}+c\right) \\
& =(1-v)\left[\Pi_{F}-\Pi_{V}\right]
\end{aligned}
$$

For firms, the surplus of a match is the instantaneous profit difference of having a filled job during the fraction of time the job will be filled. The total surplus is thus $S=S_{W}+S_{F}$ and is shared according to a bargaining between the worker and the firm. If $0 \leq \beta \leq 1$ denotes the bargaining power of workers, then the wage is defined as:

$$
w_{L}=\arg \max _{w_{L}}\left[E W-W_{U}(x)\right]^{\beta}\left(E \Pi-\Pi_{V}\right)^{1-\beta}
$$

Solving this program leads to: ${ }^{8}$

$$
w_{L}^{*}(x)=\beta(y+c)+(1-\beta)\left[w_{U}+(1-s) \tau x\right]
$$

We have the standard effects of the impact of the parameters on wages in the non-spatial search-matching model (Pissarides, 2000) where an increase in $y, c$ or $w_{U}$ increases the wage because the outside option of workers is improved. The bargaining power of workers, i.e. $\beta$, has however an ambiguous effect on $w_{L}^{*}(x)$ because two opposite effects are at work. Indeed, an increase in $\beta$ increases the wage since the worker obtains more of the surplus but because it also reduces firms' bargaining power, the firm compensates less the workers for spatial costs. The net effect is thus ambiguous. However, we will impose a condition below (see

\footnotetext{
${ }^{8}$ In the Appendix, we show that one can obtain the same wage by solving the case $r>0$, and then letting $r \rightarrow 0$.
} 
(14)), which guarantees that the productivity $y$ is always higher than wages, which in turn ensures that $w_{L}$ and $\beta$ are positively correlated.

The spatial aspect of the wage is here captured by $(1-s) \tau x$, which implies that wages increase with distance to jobs and commuting costs. Indeed, $(1-s) \tau x$ is what firms must pay to induce workers to accept the job offer since they must exactly compensate the transportation cost difference between the employed and unemployed workers at each location $x$. The fact that firms offer transport-related fringe benefits, which include monetary and nonmonetary transport benefits (company cars, travel benefits, subsidized travel, etc.), is quite common (Barber, 1998). For example, using information on firms' recruitment strategy in the United Kingdom, van Ommeren et al. (2006) show that workers' journey-to-work time induces firms to offer transport benefits to job applicants.

The fact that wages increase with distance to jobs (or equivalently with commuting time) has been already found by other theoretical models (Zenou, 2006, van Ommeren and Rietveld, 2007) and is a well-established empirical fact. For example, Manning (2003) using British data (the Labour force Survey for 1993-2001 and the British Household Panel Survey for 1991-2000) shows that an extra hour of commuting each day is associated, on average, with an increase in wages of $27 \mathrm{log}$ points. This is even truer for highly educated workers since those with more education and in the higher-status occupations are more likely to have both high wages and a long commute. These results are consistent with the ones found in the United States. For instance, Madden (1985) uses the PSID to investigate how wages vary with distance to the CBD. She finds that, for all workers who changed job, there is a positive relationship between wage change and change in commute. Zax (1991), who uses data from a single company and regresses wages on commutes, also finds a positive relationship.

For this model to make sense, it has to be that the productivity $y$ is always higher than the wage $w_{L}^{*}(x), \forall x \in[0, N]$. The condition that guarantees that this is always true is given by:

$$
y-w_{U}>\frac{\beta c}{(1-\beta)}+(1-s) \tau N
$$

Free-entry condition and labor demand Firms enter in the labor market up to the point where their expected profit is equal to zero. When they enter the labor market, they do not know which wage they will pay so ex ante they expect to pay the average wage, 
$\bar{w}_{L}(x)$, which is given by:

$$
\bar{w}_{L}(x)=w_{L}(\bar{x})=w_{L}\left(\frac{N}{2}\right)=\beta(y+c)+(1-\beta)\left[w_{U}+(1-s) \tau \frac{N}{2}\right]
$$

since workers are uniformly distributed in the city. The free-entry condition is thus $E \Pi(N / 2)=$ 0, which, using (12), leads to:

$$
q(\theta)\left[y-w_{L}(N / 2)\right]=\delta c
$$

which using $(10)$ can be written as $(1-v)\left[y-w_{L}(N / 2)\right]=v c$. This means that the expected value of a filled job is equal to the expected search cost, i.e. the cost per unit of time multiplied by the fraction of time the job is vacant. This establishes a negative relationship between job creation $\theta$ and the average wage $w_{L}(N / 2)$ since higher wages deter entry and thus reduces job creation. Plugging the value of the wage (15) into (16) yields:

$$
y-w_{U}=\left[\frac{\delta}{q\left(\theta^{*}\right)}+\beta\right] \frac{c}{(1-\beta)}+(1-s) \tau \frac{N}{2}
$$

This is the equilibrium condition that determines the job creation $\theta^{*}$. It is to see that, using (2) and (3), then, given that (14) holds, there exists a unique solution in $\theta^{*}$ for equation (17). By totally differentiating (17), we easily obtain:

$$
\begin{aligned}
\frac{\partial \theta^{*}}{\partial \delta}<0 & \frac{\partial \theta^{*}}{\partial \beta}<0 & \frac{\partial \theta^{*}}{\partial c}<0 & \frac{\partial \theta^{*}}{\partial y}>0 & \frac{\partial \theta^{*}}{\partial w_{U}}<0 \\
\frac{\partial \theta^{*}}{\partial \tau}<0 & \frac{\partial \theta^{*}}{\partial s}>0 & \frac{\partial \theta^{*}}{\partial N}<0 & \text { r } & <0
\end{aligned}
$$

The results in (18) are similar to that of the non-spatial model. Indeed, an increase (resp. decrease) in $\beta, c$, or $w_{U}$ (resp. $y$ ) deters entry and thus reduces job creation $\theta^{*}$ because it increases wages. For $\delta$, the effect is similar but goes through $u$ since higher $\delta$ implies that firms spend a lower fraction of their lifetime with a filled job. In (19), we display the results concerning the spatial variables. One can see that when $\tau$ or $N$ increases or when $s$ decreases, then firms need to compensate more workers for their spatial costs, which reduces entry and thus job creation.

\subsection{Urban land-use equilibrium}

Let us now solve the urban land use equilibrium. By plugging the wage (13) into (7), we obtain the following expected utility of a worker located at $x$ :

$$
E W(x)=w_{U}+\beta(1-u)\left[y-w_{U}+c-(1-s) \tau x\right]-s \tau x-R(x)
$$


In equilibrium, independently of $x$, all workers reach the same utility level $E W$. Therefore, the bid rent function of a worker residing at a distance $x$ from the BD can be written as: ${ }^{9}$

$$
\Psi(x, E W)=w_{U}+\beta(1-u)\left[y-w_{U}+c-(1-s) \tau x\right]-s \tau x-E W
$$

with

$$
\frac{\partial \Psi(x, E W)}{\partial x}=-[s+\beta(1-s)(1-u)] \tau<0
$$

which is decreasing and linear in $x$. This shows that the role of the land rent is to compensate workers for commuting costs and for the wage, which depends on the time they spend in each state (employment versus unemployment). Denote the agricultural land rent (the rent outside the city or opportunity rent) by $R_{A}$ and, without loss of generality, we normalize it to zero. We have:

Definition 1 An urban-land use equilibrium with high relocation costs, fixed-housing consumption and fixed search intensity is a 2-tuple $\left(E W^{*}, R^{*}(x)\right)$ such that:

$$
\begin{gathered}
\Psi\left(N, E W^{*}\right)=R_{A}=0 \\
R^{*}(x)=\max \left\{\Psi\left(x, E W^{*}\right), 0\right\} \quad \text { at each } x \in(0, N]
\end{gathered}
$$

Equation (21) says that the bid rent of the workers must be equal to the agricultural land at the city fringe while equation (22) defines the equilibrium land rent as the upper envelope of the equilibrium bid rent curves of all workers' types and the agricultural rent line.

Solving these equations leads to:

$$
\begin{aligned}
& E W^{*}=w_{U}+\beta\left[\frac{s \theta q(\theta)}{\delta+s \theta q(\theta)}\right]\left[y-w_{U}+c-(1-s) \tau N\right]-s \tau N \\
& R^{*}(x)=\left\{\begin{array}{cc}
\tau(N-x)\left[s+(1-s) \beta\left(\frac{s \theta q(\theta)}{\delta+s \theta q(\theta)}\right)\right] & \text { for } x \leq N \\
0 & \text { for } x>N
\end{array}\right.
\end{aligned}
$$

We have

$$
\frac{\partial E W^{*}}{\partial \theta}>0 \quad \frac{\partial R^{*}(x)}{\partial \theta}>0
$$

\footnotetext{
${ }^{9}$ The bid rent is a standard concept in urban economics (Fujita, 1989). It indicates the maximum land rent that a worker located at a distance $x$ from the $\mathrm{BD}$ is ready to pay in order to achieve utility level $E W$.
} 
Indeed, when $\theta$ increases, the fraction of time spent employed $(1-u)$ increases and thus workers obtain more often the wage $w_{L}$. Since $w_{L}>w_{U}$, their expected utility $E W^{*}$ increases. Workers are thus able to bid more for land, which increases the competition in the land market. This, ultimately, results in an increase in the equilibrium land rent $R^{*}(x)$ at each location $x$. The fact that land prices increase in boom periods is well-documented (see e.g. Girouard et al., 2006).

Furthermore, for a given $\theta$, we also obtain:

$$
\begin{gathered}
\left.\frac{\partial E W^{*}}{\partial y}\right|_{\theta \text { fixed }}>\left.0 \quad \frac{\partial E W^{*}}{\partial w_{U}}\right|_{\theta \text { fixed }}>\left.0 \quad \frac{\partial E W^{*}}{\partial c}\right|_{\theta \text { fixed }}>\left.0 \quad \frac{\partial E W^{*}}{\partial \beta}\right|_{\theta \text { fixed }}>0 \\
\left.\frac{\partial E W^{*}}{\partial \tau}\right|_{\theta \text { fixed }}=\left.\frac{\partial E W^{*}}{\partial N}\right|_{\theta \text { fixed }}<\left.0 \quad \frac{\partial E W^{*}}{\partial s}\right|_{\theta \text { fixed }} \gtreqless 0
\end{gathered}
$$

Indeed, when all the non-spatial parameters $\left(y, w_{U}, c, \beta\right)$ that affect positively the wage increase, then the expected utility $E W^{*}$ also increases. For the spatial parameters $\tau$ and $N$, we have the reverse effect because increasing them increases the competition in the land market so that land prices are higher, which decrease the expected utility. Finally, when $s$ increases, there are two opposite effects. On the one hand, it decreases the wage since the spatial cost difference between employment and unemployment is lower and thus firms need to compensate less their workers. On the other, it increases their chance to become employed and thus on average workers spend more time employed. The net effect is thus ambiguous.

For a given $\theta$, we also have:

$$
\left.\frac{\partial R^{*}(x)}{\partial \beta}\right|_{\theta \text { fixed }}>\left.0 \quad \frac{\partial R^{*}(x)}{\partial \tau}\right|_{\theta \text { fixed }}>\left.0 \quad \frac{\partial R^{*}(x)}{\partial N}\right|_{\theta \text { fixed }}>\left.0 \quad \frac{\partial R^{*}(x)}{\partial s}\right|_{\theta \text { fixed }} \gtreqless 0
$$

Indeed, when costs of commuting increase or the city is bigger, the competition in the land market is fiercer and thus land prices increase. Also, when workers have more bargaining power $\beta$, land rents increase because wages are higher. Finally, $s$ has an ambiguous effect on $R^{*}(x)$ because it affects both directly and indirectly (via the job acquisition rate) the competition in land market.

\subsection{Steady-state equilibrium}

Let us give a formal definition of the steady-state equilibrium. 
Definition 2 A steady-state equilibrium is a 5-tuple $\left(w_{L}^{*}(x), \theta^{*}, u^{*}, E W^{*}, R^{*}(x)\right)$ such that (13), (17), (6), (23) and (24) are satisfied.

We have the following result.

Proposition 1 If (14) holds, then there exists a unique steady-state equilibrium.

It is indeed straightforward to see that this steady-state equilibrium is unique. First, the wage is directly determined by (13) since it depends only on parameters. Then, as stated above, when (14) holds, solving (17) gives a unique solution in $\theta$, the labor-market tightness. Plugging this value in (6), we obtain the equilibrium unemployment rate $u^{*}$. Furthermore, by plugging $\theta^{*}$ in either (10) or in (1) (by using (6), the two equations are in fact equivalent), we obtain $v^{*}$. Finally, replacing $\theta^{*}$ in (23) and (24) gives respectively $E W^{*}$ and $R^{*}(x)$.

\subsection{Interaction between land and labor markets}

Let us study the general equilibrium effects on the impact of the different parameters on the expected utility $E W^{*}$ and the land rent $R^{*}(x)$. It is really the labor-market tightness $\theta$ that makes the link between the land and the labor markets. We obtain:

$$
\begin{aligned}
& \frac{\partial E W^{*}}{\partial \delta}<0 \quad \frac{\partial E W^{*}}{\partial y}>0 \quad \frac{\partial E W^{*}}{\partial w_{U}} \gtreqless 0 \quad \frac{\partial E W^{*}}{\partial c} \gtreqless 0 \quad \frac{\partial E W^{*}}{\partial \beta} \gtreqless 0 \\
& \frac{\partial E W^{*}}{\partial \tau} \gtreqless 0 \quad \frac{\partial E W^{*}}{\partial N} \gtreqless 0 \quad \frac{\partial E W^{*}}{\partial s} \gtreqless 0
\end{aligned}
$$

Observe first that, by looking at (23), one can see that the effect of $\delta$ on $E W^{*}$ is only indirect via $\theta$ and is negative since higher $\delta$ increases the fraction of time one spends unemployed, which reduces the expected utility. For all the other parameters, there are always two effects: a direct one and an indirect one via $\theta$. Concerning the productivity $y$, the effect on $E W^{*}$ is always positive because it directly increases the wage and thus the expected utility (see (26)) but it also increases job creation and thus the time spent employed. For $w_{U}$ and $c$, the effects are ambiguous because it has a direct positive effect (see (26)) but an indirect negative effect via $\theta$ since it increases wages but reduces job creation (see (18)). Concerning the spatial variables $\tau$ and $N$, increasing them always reduces the expected utility $E W^{*}$ because it both reduces job creation and increases the competition in the land market. Finally, the 
ambiguity of $\beta$ and $s$ stems from the same types of direct and indirect effect via $\theta$. We also have the following results.

$$
\begin{aligned}
& \frac{\partial R^{*}(x)}{\partial y}>0 \quad \frac{\partial R^{*}(x)}{\partial w_{U}}<0 \quad \frac{\partial R^{*}(x)}{\partial c}<0 \quad \frac{\partial R^{*}(x)}{\partial \delta}<0 \quad \frac{\partial R^{*}(x)}{\partial \beta} \gtreqless 0 \\
& \frac{\partial R^{*}(x)}{\partial \tau} \gtreqless 0 \quad \frac{\partial R^{*}(x)}{\partial N} \gtreqless 0 \quad \frac{\partial R^{*}(x)}{\partial s} \gtreqless 0
\end{aligned}
$$

First, the parameters $y, \delta, c$ and $w_{U}$ affect the equilibrium land rent $R^{*}(x)$ only indirectly through $\theta^{*}$. For example, when job matches are more productive, $y$ increases, and thus firms create more jobs, which leads to an increase of $\theta$. The latter implies that there is more competition in the land market and thus land prices are augmented at all locations $x \in[0, N]$. The same reasoning applies for $\delta, c$ and $w_{U}$, even though the effects are negative. It is particularly interesting to see that an increase in unemployment benefits $w_{U}$ leads to lower land prices. This does not seem to be contradicted by what we observe when we compare countries like the UK, which have low unemployment benefits, and other European countries such as France, Germany or Spain, where unemployment benefits are higher. It is indeed well-known that London is a much expensive place to live than Paris, Berlin or Madrid. Of course a thorough econometric test of this relationship will be very welcome and the results very important for policy issues. Second, the bargaining power of workers, $\beta$, acts both directly and indirectly through on $R^{*}(x)$. Indeed, it is easy to check that

$$
\operatorname{sign} \frac{\partial R^{*}(x)}{\partial \beta}=\operatorname{sign}\left[\frac{s \theta q(\theta)}{\delta+s \theta q(\theta)}+\beta \frac{\partial(1-u)}{\partial \theta} \frac{\partial \theta}{\partial \beta}\right]
$$

where the first and last sign are derived using (28) and (18), respectively. There is a direct positive effect since a higher $\beta$ implies higher wages and thus more capacity to pay for land. There is also an indirect negative effect since a higher $\beta$, which increases the wage, also reduces the job creation rate $\theta$, and thus the time workers spend employed. This, in turn, reduces their bid rent. The net effect is thus ambiguous. Finally, the effects of commuting costs $\tau$ and city size $N$ on $R^{*}(x)$ are ambiguous. Indeed, when $\tau$ or $N$ increases, there is a direct positive effect on land rents because the access to jobs becomes more important (see (28)) but there is also an indirect negative effect on land rents via $\theta^{*}$ since wages increase, firms create less jobs and thus workers spend more time unemployed and bid less for land. 


\subsection{Welfare and efficiency}

As in the standard search-matching literature (Mortensen and Pissarides, 1999, Pissarides, 2000), in the present model, market failures are caused by search externalities. We would like now to see if the land market with high-relocation costs create additional market failures.

Let us study the welfare of this economy. The social welfare function is given by the sum of the utilities of the employed and the unemployed, the production of the firms net of search costs and the land rents received by the (absentee) landlords. The wage $w_{L}$ as well as the land rent $R(x)$, being pure transfers, are thus excluded in the social welfare function. When $r \rightarrow 0$, the latter is therefore given by:

$$
\begin{aligned}
\mathcal{W} & =\int_{0}^{N}(1-u)(y-\tau x) d x+\int_{0}^{N} u\left(w_{U}-s \tau x\right) d x-v c \\
& =(1-u)\left[y N-\tau \frac{N^{2}}{2}\right]+u\left[w_{U} N-s \tau \frac{N^{2}}{2}\right]-\theta s u N c
\end{aligned}
$$

Indeed, each worker located at $x \in[0, N]$, spends $1-u$ fraction of his/her lifetime employed, where he/she produces $y$ while spending $\tau x$ in commuting costs, and $u$ fraction of his/her lifetime unemployed, where he earns $w_{U}$ and spends $s \tau x$ in commuting costs. Firms (whose total mass is 1 ) spend $v=\theta s u N$ fraction of their lifetime vacant, which cost them $c$. The planner solves: $\max _{\theta, u} \mathcal{W}$, subject to the constraint (6). The solution of this maximization problem leads to:

$$
y-w_{U}=\left[\frac{\delta}{q(\theta)}+s \theta \eta(\theta)\right]\left[\frac{c}{1-\eta(\theta)}\right]+(1-s) \tau \frac{N}{2}
$$

where

$$
\eta(\theta)=-\frac{q^{\prime}(\theta)}{q(\theta)} \theta
$$

is the elasticity of $q(\theta)$, the firm's contact rate. Comparing (29) with the market solution (17), we obtain the following result:

\section{Proposition 2 If}

$$
\beta=\frac{[\delta+s \theta q(\theta)] \eta(\theta)}{\delta+q(\theta)[1-\eta(\theta)(1-s \theta)]}
$$

holds, then the private and the social outcomes coincide. 
In the standard non-spatial search-matching models, Hosios (1990) and Pissarides (2000) have established that search equilibrium is socially efficient if and only if the matching function is homogenous of degree one (like here) and the worker's share of surplus $\beta$ is equal to $\eta(\theta)$ the elasticity of the matching function with respect to unemployment. This is referred to as the Hosios-Pissarides condition. Here this condition does not hold and in fact (30) can be considered as a spatial Hosios-Pissarides condition since high-relocation costs imply new inefficiencies. Indeed, if one uses exactly the same spatial model as this one, but with zero-relocation costs (as in Wasmer and Zenou, 2002, and Zenou, 2007, chap. 1), then the non-spatial Hosios-Pissarides condition, i.e. $\beta=\eta(\theta)$, holds and guarantees that the market solution is efficient. As a result, the fact that the standard Hosios-Pissarides condition does not hold here is because high-relocation costs, which means that workers are stuck to their residential location, creation additional frictions and externalities.

\section{Search intensity as a function of distance to jobs}

So far workers' search intensity was exogenous and independent of residential location. There are strong evidence showing that distance to jobs does impact on search behavior. Indeed, Barron and Gilley (1981) and Chirinko (1982) have shown that there are diminishing returns to search when people live far away from jobs. Rogers (1997) have also demonstrated that access to employment is a significant variable in explaining the probability of leaving unemployment. Finally, Seater (1979) have shown that workers searching further away from their residences are less productive in their search activities than those who search closer to where they live.

Following Wasmer and Zenou (2002), we would like to endogeneize $s$ by assuming that

$$
s(x)=s_{0}-s_{a} x
$$

where $s_{0}>0$ and $s_{a}>0$. In this formulation, $s_{0}$ is the part of the search intensity that is not affected by distance to jobs while $s_{a}$ is the marginal decrease in search intensity per unit of distance. Since the job acquisition rate is defined as: $\left(s_{0}-s_{a} x\right) \theta q(\theta)$, then $s_{a} \theta q(\theta)$ is the marginal decrease in the job acquisition rate for an unemployed worker. When $s_{a}=0$, we are back to the previous model. In order for the search intensity to be always positive and 
to be less than 1 whatever $x \in[0, N]$, we impose that

$$
s_{a} N<s_{0}<1
$$

So, with this formulation, when workers are further away from jobs, they search less intensively. ${ }^{10}$ Moreover, $\bar{s}$, the aggregate search efficiency in a city will now depend on the average location of the unemployed. Since workers are fixed to their location and do not relocate, it is given by

$$
\begin{aligned}
\bar{s} & =s_{0}-s_{a} \bar{x} \\
& =s_{0}-s_{a} \frac{N}{2}
\end{aligned}
$$

Each individual located in $x$ will in that case experience the following unemployment rate

$$
u(x)=\frac{\delta}{\delta+s(x) \theta q(\theta)}
$$

which is the fraction of his/her lifetime when he/she is unemployed. Because $s^{\prime}(x)<0$, this means, in particular, that $u^{\prime}(x)>0$ because workers residing further away from jobs search less intensively. The flows in and out unemployment is given by

$$
\int_{0}^{N} 1_{x} s(x) \theta q(\theta) d x=(1-u) N \delta
$$

where $1_{x}$ is an indicator function that is equal to 1 if the worker is unemployed and zero otherwise. However, since in steady-state, workers have been employment and unemployed during $1-u$ and $u$ fraction of their time, and since the average search intensity is $\bar{s}=$ $\frac{1}{N} \int_{0}^{N} s(x) d x$, we have

$$
\int_{0}^{N} 1_{x} s(x) \theta q(\theta) d x=\theta q(\theta) \int_{0}^{N} 1_{x} s(x) d x=\theta q(\theta) \int_{0}^{N} u s(x) d x=\theta q(\theta) u \bar{s} N
$$

By combining (35) and (36), we obtain the unemployment rate of this economy, which is equal to:

$$
u=\frac{\delta}{\delta+\bar{s} \theta q(\theta)}
$$

\footnotetext{
${ }^{10}$ See Smith and Zenou (2003) and Wasmer and Zenou (2006) for model of endogenous search intensity $s$ showing that $s$ is indeed a negative function of distance to jobs $x$.
} 
In that context, the workers' instantaneous utilities are given by:

$$
W_{L}(x)=w_{L}(x)-\tau x-R(x)
$$

and

$$
W_{U}(x)=w_{U}-s(x) \tau x-R(x)
$$

for the employed and unemployed, respectively. As a result, the expected utility of a worker residing in $x$ is given by:

$$
\begin{aligned}
E W(x) & =[1-u(x)] W_{L}(x)+u(x) W_{U}(x) \\
& =w_{L}(x)-\tau x-R(x)-\frac{\delta\left\{w_{L}(x)-w_{U}-[1-s(x)] \tau x\right\}}{\delta+s(x) \theta q(\theta)}
\end{aligned}
$$

where $s(x)$ is defined by $(31)$.

\subsection{Labor-market equilibrium}

The firms' expected utility is as before and given by (12). Using the same wage determination procedure as in the previous section, we easily obtain:

$$
\begin{aligned}
w_{L}^{*}(x) & =\beta(y+c)+(1-\beta)\left\{w_{U}+[1-s(x)] \tau x\right\} \\
& =\beta(y+c)+(1-\beta)\left\{w_{U}+\left(1-s_{0}\right) \tau x+s_{a} \tau x^{2}\right\}
\end{aligned}
$$

We have the same effects as before with one difference is that the wage is increasing and convex (and not anymore linear) in distance $x$. Again we need a condition that guarantees that $y>w_{L}^{*}(x), \forall x \in[0, N]$. We have:

$$
y(1-\beta)>\beta c+(1-\beta)\left\{w_{U}+\left(1-s_{0}\right) \tau N+s_{a} \tau N^{2}\right\}
$$

The free-entry condition is given by $E \Pi(N / 2)=0$, which, using (12) and (38) is equivalent to:

$$
y-w_{U}=\left[\frac{\delta}{q\left(\theta^{*}\right)}+\beta\right] \frac{c}{(1-\beta)}+\left(1-s_{0}\right) \tau \frac{N}{2}+s_{a} \tau\left(\frac{N}{2}\right)^{2}
$$

This is the equilibrium condition that determines the job creation $\theta^{*}$ and, using (39), one can see that there exists a unique solution in $\theta^{*}$ to $(40)$. 


\subsection{Urban land-use and steady-state equilibrium}

As before, using the wage (38), we can calculate the expected utility of a worker located at $x:$

$$
E W(x)=w_{U}+\beta[1-u(x)]\left\{y-w_{U}+c-[1-s(x)] \tau x\right\}-s(x) \tau x-R(x)
$$

and their bid rent:

$$
\Psi(x, E W)=w_{U}+\beta[1-u(x)]\left\{y-w_{U}+c-[1-s(x)] \tau x\right\}-s(x) \tau x-E W
$$

with

$$
\begin{aligned}
\frac{\partial \Psi(x, E W)}{\partial x}= & -\beta u^{\prime}(x)\left\{y-w_{U}+c-\left[1-s_{0}+s_{a} x\right] \tau x\right\}-\beta \tau[1-u(x)] \\
& -\left(s_{0}-2 s_{a} x\right) \tau\{1-\beta[1-u(x)]\}
\end{aligned}
$$

Since $u^{\prime}(x)>0$, a sufficient condition for the bid rent to be always negative is

$$
2 s_{a} N<s_{0}<1
$$

which is a slightly stronger condition than (32). Here the land rent compensates workers not only for commuting costs and wages, as before, but also for their unemployment rate (or more exactly the fraction of their lifetime when they are unemployed) since the further away someone resides, the lower is the search intensity and the higher the time spent unemployed. Using Definition 1, we easily obtain:

$$
\begin{gathered}
E W^{*}=w_{U}+\beta[1-u(N)]\left\{y-w_{U}+c-[1-s(N)] \tau N\right\}-s(N) \tau N \\
R^{*}(x)=\left\{\begin{array}{cc}
\beta\left[y-w_{U}+c\right][u(N)-u(x)]+\tau[s(N) N-s(x) x] & \text { for } x \leq N \\
+\tau \beta\{[1-u(N)][1-s(N)] N-[1-s(x)][1-u(x)] x\} & \text { for } x>N \\
0 & x
\end{array}\right.
\end{gathered}
$$

with $s(N)=s_{0}-s_{a} N$ and $u(N)=\delta /[\delta+s(N) \theta q(\theta)]$.

Finally, using Definition 2, it is straightforward to show that there exists a unique steadystate equilibrium if (39) holds. 


\section{Spatial mismatch}

As stated in the introduction, there is an important empirical literature on the spatial mismatch hypothesis (SMH). There are however few theoretical models that try to give the exact mechanism that explains what being further away from jobs can have adverse labormarket outcomes for ethnic minorities (Gobillon et al., 2007). Here, based on the model of the previous section, we would like to give some theoretical foundation explaining the spatial mismatch between jobs and black workers' residential location.

Assume now that there are two types of workers, black and white (identified by superscript $i=B, W$, respectively) whose mass are respectively given by $N^{B}$ and $N^{W}$, with $N=$ $N^{B}+N^{W}$. Black and white workers have the same productivity $y$ and thus firms have no preference to hire one type of workers (there is no discrimination). The only difference between black and white workers is due to the fact that the job contact rate is different. Indeed, we assume that the job contact rate for a type- $i$ worker located at $x$ is given by $\alpha^{i} s(x) \theta q(\theta)$, where $\alpha^{B}=\alpha<\alpha^{W}=1$. This reflects the fact that blacks and whites have different social networks because blacks tend to be friends with blacks and whites with whites (see e.g. Sigelman et al., 1996). ${ }^{11}$ Since employers are mostly whites and a fraction of them tend to recruit workers via word-of-mouth and friends, ${ }^{12}$ then obviously two workers $B$ and $W$ located at the same distance $x$ (and thus having the same $s(x)$ ) will not have the same chance to have a contact with a firm. This, in particular, implies that, when a black worker searches with intensity $s(x)$, his/her returns from search is $\alpha s(x)$ (with $0<\alpha<1$ ) while for whites it is exactly $s(x)$. So there are lower returns to search for black workers.

In this context, the expected utility of a type- $i$ worker is then given by:

$$
\begin{aligned}
E W^{i}(x) & =\left[1-u^{i}(x)\right] W_{L}^{i}(x)+u^{i}(x) W_{U}^{i}(x) \\
& =\left[1-u^{i}(x)\right]\left[w_{L}(x)-\tau x\right]+u^{i}(x)\left[w_{U}-s(x) \tau x\right]-R(x)
\end{aligned}
$$

\footnotetext{
${ }^{11}$ For example, Wial (1991) shows that, because blacks and whites have different social networks, white workers tend to have better jobs and better opportunities than black workers.

${ }^{12}$ Sociologists and labor economists have produced a broad empirical literature on labor market networks. In fact, the pervasiveness of social networks and their relative effectiveness varies with the social group considered. For instance, Holzer (1988) shows that among 16-23 year old workers who reported job acceptance, $66 \%$ use informal search channels (30\% direct application without referral and $36 \%$ friends/relatives), while only $11 \%$ use state agencies and $10 \%$ newspapers. See also Corcoran et al. (1980) and Granovetter (1995) and for a literature survey Ioannides and Loury (2004).
} 
where

$$
u^{i}(x)=\frac{\delta}{\delta+\alpha^{i} s(x) \theta q(\theta)}
$$

The wage is still given by (38) and only depends on the location of the workers. As a result the bid rent of a type- $i$ worker located at a distance $x$ from the job center is equal to:

$$
\begin{aligned}
\Psi^{i}\left(x, E W^{i}\right)= & {\left[1-u^{i}(x)\right]\left[w_{L}(x)-\tau x\right]+u^{i}(x)\left[w_{U}-s(x) \tau x\right]-E W^{i} } \\
= & {\left[1-u^{i}(x)\right]\left[\beta(y+c)+(1-\beta) w_{U}-\beta \tau x-(1-\beta) s(x) \tau x\right] } \\
& +u^{i}(x)\left[w_{U}-s(x) \tau x\right]-E W^{i}
\end{aligned}
$$

As in the previous section, assuming (41), the bid rent of a type- $i$ worker is decreasing in $x$, and it is easy to show that, $\forall x$, we have:

$$
\left|\frac{\partial \Psi^{W}\left(x, E W^{W}\right)}{\partial x}\right|>\left|\frac{\partial \Psi^{B}\left(x, E W^{B}\right)}{\partial x}\right|
$$

The intuition is straightforward. Since $\alpha^{B}=\alpha<\alpha^{W}=1$, then, at each $x, u^{B}(x)>$ $u^{W}(x)$, which implies that black workers spend more time unemployed over their lifetime than whites and thus have lower expected commuting costs since the latter are equal to: $\left[1-u^{i}(x)\right] \tau x+u^{i}(x) s(x) \tau x$ for a type- $i$ worker. As a result, white workers have steeper bid rents than blacks and thus bid away black workers in order to reside closer to jobs. We have the following result:

Proposition 3 If blacks and whites only differ by their contact rate $\alpha^{i}$, then black workers reside further away from jobs, search less intensively, have a lower expected wage, and experience higher spells of unemployment than white workers.

This is an interesting result that can be explained as follows. Because blacks have a lower contact rate than whites, they are more often unemployed and thus have flatter bid rents than whites. As a result, they reside further away from jobs. This implies that black workers search less intensively than whites, i.e. $s^{B}(x)<s^{W}(x), \forall x$, and are thus even more unemployed since now both $\alpha^{i}$ and $s^{i}(x)$ are lower. Space, by separating black and white workers in the city, amplifies the effect on unemployment. Moreover, the expected wage of a type $-i$ worker is given by:

$$
\left[1-u^{i}(x)\right] w_{L}(x)+u^{i}(x) w_{U}
$$


Since $\forall x, u^{W}(x)<<u^{B}(x)$, then the expected wage of whites will be much higher than that of blacks, even though they are more compensated for their spatial costs when they work.

Observe that the locational pattern obtained here, i.e. whites live between $x=0$ and $x=N_{W}$ while blacks reside between $x=N_{W}$ and $x=N$, can capture both the European and American situations. Indeed, in Europe, ethnic minorities tend to live in the suburbs far away from jobs. This is what we have here if we interpret the BD as the Central Business District (CBD). In the US, blacks tend to live at the vicinity of the city-center but far away from jobs since cities tend to be more and more decentralized in terms of jobs (see e.g. Glaeser et al., 2007). If the BD is interpreted as the Suburban Business District (SBD), then we have this pattern. What is crucial here is that, both in Europe and in the US, ethnic minorities tend to be far away from jobs.

To close the model, we need to write the free-entry condition. When a new firm enters the market it does not know which location and which type of worker it will hire. As a result, the free-entry condition is given by:

$$
\frac{N^{W}}{N} E \Pi^{W}\left(\frac{N^{W}}{2}\right)+\left(1-\frac{N^{W}}{N}\right) E \Pi^{B}\left(\frac{N+N^{W}}{2}\right)=0
$$

where

$$
\begin{aligned}
E \Pi^{i}(x) & =\left[\frac{q(\theta)}{\delta+q(\theta)}\right]\left[y-w_{L}^{i}(x)\right]-\frac{\delta}{\delta+q(\theta)} c \\
& =\left[\frac{q(\theta)}{\delta+q(\theta)}\right]\left[(1-\beta)\left[y-w_{U}-\left(1-s_{0}\right) \tau x-s_{a} \tau x^{2}\right]-\beta c\right]-\frac{\delta}{\delta+q(\theta)} c
\end{aligned}
$$

Equation (44) is easy to understand. If a new firm enters the labor market, then, with probability $N^{W} / N$, it can hire a white worker, whose average location is $N_{W} / 2$, while, with probability $1-N^{W} / N$, it can hire a black worker, whose average location is $\left(N+N^{W}\right) / 2$. Solving the free-entry condition (44) leads to

$$
y-w_{U}=\left[(1+\beta) \frac{\delta}{q(\theta)}+\beta\right] \frac{c}{(1-\beta)}+\left(1-s_{0}\right) \tau \frac{N}{2}+s_{a} \tau\left[\frac{N^{2}+N N_{W}-N_{W}^{2}}{4}\right]
$$

We can now define the urban land-use equilibrium as follows:

Definition 3 An urban-land use equilibrium with black and white workers, high relocation costs, and fixed-housing consumption is a 3-tuple $\left(E W^{B *}, E W^{W *}, R^{*}(x)\right)$ such that:

$$
\Psi\left(N^{W}, E W^{B *}\right)=\Psi\left(N^{W}, E W^{W *}\right)
$$




$$
\begin{gathered}
\Psi\left(N, E W^{B *}\right)=R_{A}=0 \\
R^{*}(x)=\max \left\{\Psi\left(x, E W^{B *}\right), \Psi\left(x, E W^{W *}\right), 0\right\} \quad \text { at each } x \in(0, N]
\end{gathered}
$$

Equations (46) and (47) reflect the equilibrium conditions in the land market. Equation (46) says that, in the land market, at the frontier $N^{W}$, the bid rent offered by white workers is equal to the bid rent offered by black workers. Equation (47), in turn, says that the bid rent of black workers at the city-fringe must be equal to the agricultural land. Finally, as in the previous section, equation (48) defines the equilibrium land rent as the upper envelope of the equilibrium bid rent curves of all workers and the agricultural rent line.

By solving the first two equations, we obtain:

$$
\begin{aligned}
& E W^{B}=\left[1-u^{B}(N)\right] \beta(y+c-\tau N)+\left[1-\beta\left(1-u^{B}(N)\right)\right]\left[w_{U}-s(N) \tau N\right] \\
& E W^{W}=\left[u^{B}\left(N^{W}\right)-u^{W}\left(N^{W}\right)\right] \beta\left[y-w_{U}+c-\left(1-s\left(N^{W}\right)\right) \tau N^{W}\right]+E W^{B}
\end{aligned}
$$

Finally, by plugging these values into the bid rent function, we get:

$$
\begin{aligned}
R^{*}(x)= & {\left[1-u^{i}(x)\right]\left[\beta(y+c)+(1-\beta) w_{U}-\beta \tau x\right]-s(x) \tau x\left[1-\beta\left(1-u^{W}(x)\right)\right] } \\
& +u^{i}(x) w_{U}-E W^{W}
\end{aligned}
$$

for $0 \leq x \leq N^{W}$, and

$$
\begin{aligned}
R^{*}(x)= & {\left[1-u^{B}(x)\right][\beta(y+c-\tau x)]-\left[1-u^{B}(N)\right] \beta(y+c-\tau N) } \\
& +\left[1-\beta\left(1-u^{B}(x)\right)\right]\left[w_{U}-s(x) \tau x\right]-\left[1-\beta\left(1-u^{B}(N)\right)\right]\left[w_{U}-s(N) \tau N\right]
\end{aligned}
$$

for $N^{W}<x \leq N$

\section{Conclusion}

Most empirical studies show that there are substantial relocation costs for moving, in particular transaction costs. In the present paper, we have investigated this issue in the context 
of a search-matching model. For that, we have developed a simple model where both search and spatial frictions exist. We have characterized the steady-state equilibrium and shown that its is not efficient. We have also provided a spatial Pissarides-Hosios condition, which guarantees that the market and the social outcomes coincide. We have then extended the basic model to take into account a well-observed empirical fact: the negative relationship between search intensity and distance to jobs. This model have then helped us to explain why black workers reside far away from jobs, experience higher spells of unemployment and have lower wages than white workers.

\section{References}

[1] Barber, A. (1998), Recruiting Employees: Individual and Organizational Perspectives, London: Sage Publications.

[2] Barron, J.M. and O. Gilley (1981), "Job search and vacancy contacts: Note," American Economic Review 71, 747-752.

[3] Chirinko, R. (1982), "An empirical investigation of the returns to search," American Economic Review 72, 498-501.

[4] Corcoran, M., Datcher, L., and G.J. Duncan (1980), "Most workers find jobs through word of mouth," Monthly Labor Review 103, 33-35.

[5] Coulson, E., Laing, D., and P. Wang (2001), "Spatial mismatch in search equilibrium," Journal of Labor Economics 19, 949-972.

[6] Fujita, M. (1989), Urban Economic Theory, Cambridge: Cambridge University Press.

[7] Girouard, N., Kennedy, M., van den Noord, P., and C. André (2006), "Recent house price developments: The role of fundamentals," OECD Economics Department Working Papers No. 475.

[8] Glaeser, E.L., M.E. Kahn and J. Rappaport (2007), "Why do the poor live in cities? The role of public transportation," Journal of Urban Economics, forthcoming. 
[9] Gobillon, L. and H. Selod (2007), "The effect of segregation and spatial mismatch on unemployment: Evidence from France", Unpublished manuscript, INRA.

[10] Gobillon, L. Selod, H. and Y. Zenou (2007), "The mechanisms of spatial mismatch," Urban Studies, forthcoming.

[11] Granovetter, M.S. (1995), Getting a Job: A Study of Contacts and Careers, Cambridge, MA: Harvard University Press.

[12] Holzer, H. (1988), "Search method used by unemployed youth," Journal of Labor Economics 6, 1-20.

[13] Hosios, A. (1990), "On the efficiency of matching and related models of search and unemployment," Review of Economic Studies 57, 279-298.

[14] Ihlanfeldt, K. and Sjoquist, D. (1998), "The spatial mismatch hypothesis: A review of recent studies and their implications for welfare reform," Housing Policy Debate 9, 849-92.

[15] Ioannides, Y. and L.D. Loury (2004), "Job information networks, neighborhood effects, and inequality," Journal of Economic Literature 42, 1056-1093.

[16] Kain, J. (1968), "Housing segregation, negro employment, and metropolitan decentralization," Quarterly Journal of Economics 82, 32-59.

[17] Madden, J.F. (1985), "Urban wage gradients: Empirical evidence," Journal of Urban Economics 18, 291-301.

[18] Manning, A. (2003), "The real thin theory: Monopsony in modern labour markets," Labour Economics 10, 105-131.

[19] Mortensen, D.T. and C.A. Pissarides (1999), "New developments in models of search in the labor market," in Handbook of Labor Economics, D. Card and O. Ashenfelter (Eds.), Amsterdam: Elsevier Science, ch.39, pp. 2567-2627.

[20] Patacchini, E. and Y. Zenou (2005), "Spatial mismatch, transport mode and search decisions in England," Journal of Urban Economics 58, 62-90. 
[21] Pissarides, C.A. (2000), Equilibrium Unemployment Theory, Second edition, Cambridge (MA): MIT Press.

[22] Rogers, C.L. (1997), "Job search and unemployment duration: Implications for the spatial mismatch hypothesis," Journal of Urban Economics 42, 109-132.

[23] Sato, Y. (2001), "Labor heterogeneity in an urban labor market," Journal of Urban Economics 50, 313-337.

[24] Sato, Y. (2004), "City structure, search, and workers' job acceptance behavior," Journal of Urban Economics 55, 350-370.

[25] Seater, J. (1979), "Job search and vacancy contacts," American Economic Review 69, 411-419.

[26] Selod, H. and Y. Zenou (2006), "City structure, job search, and labour discrimination. Theory and policy implications," Economic Journal 116, 1057-1087.

[27] Sigelman, L., Bledsoe, T., Welch, S., and M.W. Combs (1996), "Making contact? Blackwhite social interaction in an urban setting," American Journal of Sociology 101, 13061332 .

[28] Simpson, W. (1992), Urban Structure and the Labour Market. Worker Mobility, Commuting, and Underemployment in Cities, Oxford: Clarendon Press.

[29] Smith, T.E. and Y. Zenou (2003), "Spatial mismatch, search effort and urban spatial structure," Journal of Urban Economics 54, 129-156.

[30] Van Ommeren, J. and M. van Leuvensteijn (2005), "New evidence of the effect of transaction costs on residential mobility," Journal of Regional Science 45, 681-702.

[31] Van Ommeren, J. and P. Rietveld (2007), "Commuting and reimbursement of residential relocation costs," Journal of Transport Economics and Policy 41, 51-73.

[32] Van Ommeren, J., van der Vlist, A., and P. Nijkamp (2006), "Transport-related fringe benefits: Implications for moving and the journey to work," Journal of Regional Science 46, 493-506. 
[33] Wasmer, E. and Y. Zenou (2002), "Does city structure affect job search and welfare?" Journal of Urban Economics 51, 515-541.

[34] Wasmer, E. and Y. Zenou (2006), "Equilibrium search unemployment with explicit spatial frictions," Labour Economics 13, 143-165.

[35] Wial, H. (1991), "Getting a good job: Mobility in a segmented labor market," Industrial Relations 30, 396-416.

[36] Zax, J.S. (1991), "Compensation for commutes in labor and housing markets," Journal of Urban Economics 30, 192-207.

[37] Zenou, Y. (2006), "Efficiency wages and unemployment in cities: The case of high relocation costs," Regional Science and Urban Economics 36, 49-71.

[38] Zenou, Y. (2007), Urban Labor Economics, Cambridge: Cambridge University Press, forthcoming. 


\section{Appendix}

\section{Calculation of the wage}

When $r>0$, we have the following standard steady-state Bellman equations for the lifetime expected utilities of the employed $I_{L}$ and unemployed $I_{U}$ :

$$
\begin{gathered}
r I_{L}=w_{L}-\tau x-R(x)-\delta\left(I_{L}-I_{U}\right) \\
r I_{U}=w_{U}-s \tau x-R(x)+s \theta q(\theta)\left(I_{L}-I_{U}\right)
\end{gathered}
$$

By combining (51) and (52), we obtain:

$$
I_{L}-I_{U}=\frac{w_{L}-w_{U}-(1-s) \tau x}{r+\delta+s \theta q(\theta)}
$$

Denote respectively by $I_{F}$ and $I_{V}$ the intertemporal profit of a firm with a job and with a vacancy. The steady-state Bellman equations can then be written as:

$$
\begin{gathered}
r I_{F}=y-w_{L}-\delta\left(I_{F}-I_{V}\right) \\
r I_{V}=-c+q(\theta)\left(I_{F}-I_{V}\right)
\end{gathered}
$$

By combining (54) and (55), we obtain:

$$
I_{F}-I_{V}=\frac{y-w_{L}+c}{r+\delta+q(\theta)}
$$

The Nash bargaining program is defined as:

$$
w_{L}=\arg \max _{w_{L}}\left(I_{L}-I_{U}\right)^{\beta}\left(I_{F}-I_{V}\right)^{1-\beta}
$$

By using (53) and (56), setting $r=0$, and solving this program, we obtain (13). 